\title{
Universidad gratis ¿Quién gana, quién pierde?
}

Por Eduardo Saavedra*.

"Profesor Facultad de Economia y
Negocios, UAH. Doctor en Economia,

Negocios, UAH. Doctor en Economi
Cornell University, EE.UU.

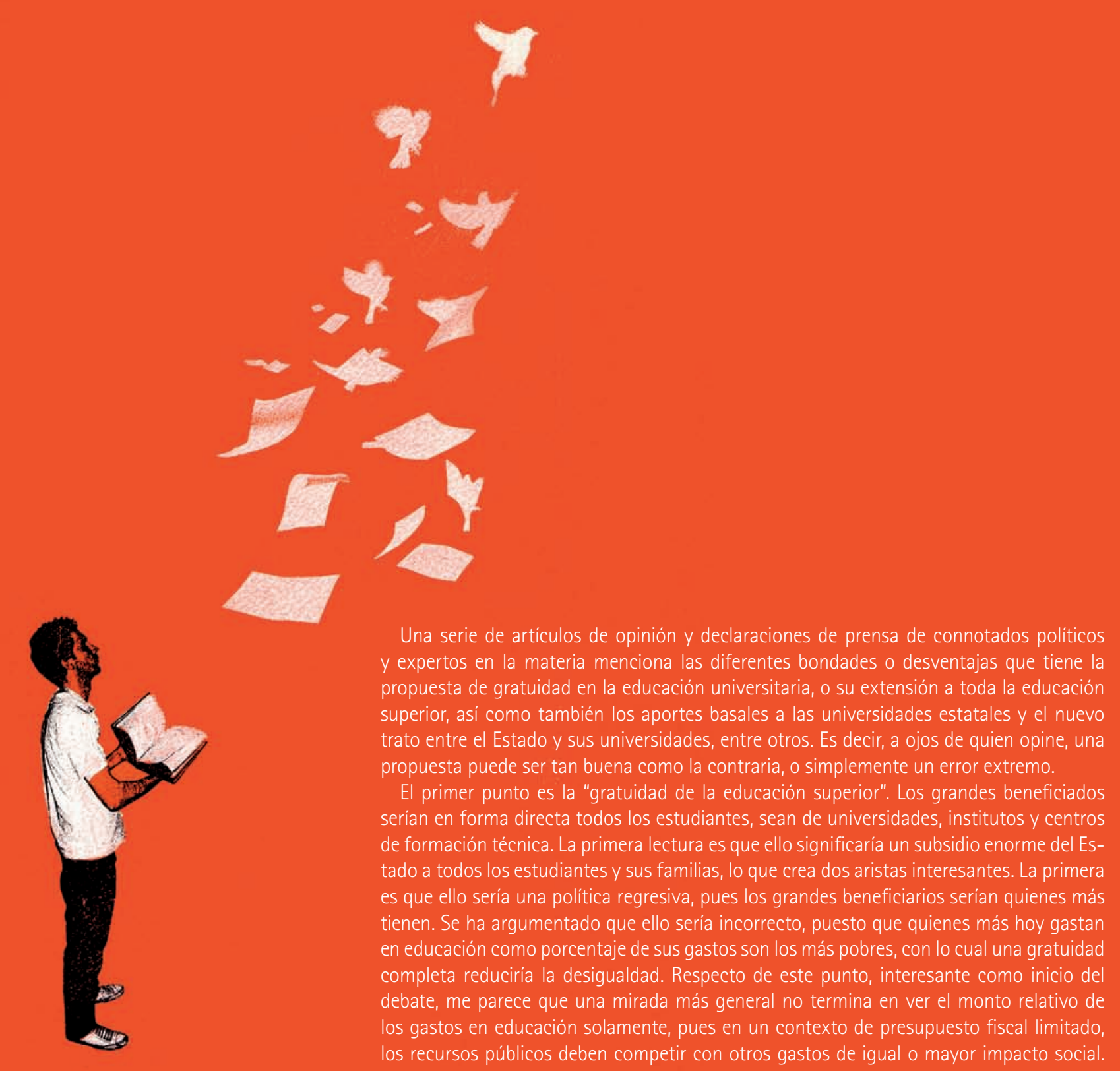

Asi, en tanto los recursos que se destinen a contexto de presupuesto público limitado, de manera de asegurar trabajo, financiafinanciar la gratuidad de la educación sean $y$ ad extraidos integramente del presupuesto de sostener un nivel minimo de la calidad de la que los usan para fines públicos y muchas la nación, la medida tendria un impacto educación. En otras palabras, los estudian- veces privados tambièn. A ello se suman regresivo, pues se desplazarian inversiones tes son consistentes en su petición, aun las universidades privadas que, por haber que benefician directa o indirectamente a cuando en mil opinión esa no es la mejor sido fundadas antes del año 1981, tienen los más pobres, como son el gasto en salud educación escolar, vivienda, obras pública más pobres, pues gratuidad y educación gasto focalizado ADEMÁS de una reforma La segunda arista tiene que ver con que completamente fuera de lugar. Hoy existen un coniunto de universidades públicas y privadas, algunas de ellas "tradicionales" y otras nuevas (y sin mayores derechos fondos públicos), institutos de educación superior y centros de formación técnica.
Por de pronto, la gratuidad generalizada romperia una serie de privilegios que tienen las actuales universidades estatales y muchas de las privadas tradicionales
(Pontificia Universidad Católica, Pontificia (Pontificia Universidad Católica, Pontificia
Universidad Católica de Valparaiso, Universidad Técnica Federico Santa Maria, Universidad Tenca Federico Santa Marla, Universidad de Concepción, Universidad catôlica el Consejo de Rectores de Universidades tos del Estado (desde los aportes direcnación) a estas universidades -conocido como AFD- y créditos estatales con tasas subsidiadas. De más está decir que en un nuevo contexto de gratuidad no tendría sentido que el Estado además dispusiera de otros cuantiosos recursos a sus universidades protegidas, lo que sin duda moveria el mapa de forma tal que las piezas alli colocadas tomarian una posicion muy beneficiadas fueran las mismas que en la actualidad.

Gratuidad y algo más

Como consecuencia de lo anterior, to único claro es que la propuesta de fondo no puede ser solamente gratuidad. Los estudiantes y el colegio de profesores plantean que una reforma solo es posible si va acompañada de una reforma tributaria. La razón de fondo es económicamente simple: se garantizaria que la reforma no impactara en los gastos sociales del gobierno en recidos a sus pares estatales. Todo trato dicriminatorio en este sentido pone una - A partir de la opción de gratuidad con cuna entre estas universidades y las priva0 sin reforma tributaria, las universidades das creadas a partir de los años ochenta, lo al ruedo: exigen un que genera una distorsión en la asignación nevo trato de parte del dueno. Es decir, a de recursos y regalias a un grupo de presión riorevuelto... Ellas buscan sellar la situación poderoso.

de privilegio de la que gozan asegurandose Otras peticiones ya son definitivamente mortes basales para su sustento. Cierta- más ideológicas, como aquellas que buscan mente estariamos frente a un trato discri- por ley eliminar la propiedad privada en niva "avos recursos se asignen en base a pros" como la norma constitucional que eliminó ague consistiendo a habno... el "merito la propiedad publica en muchos sectores de

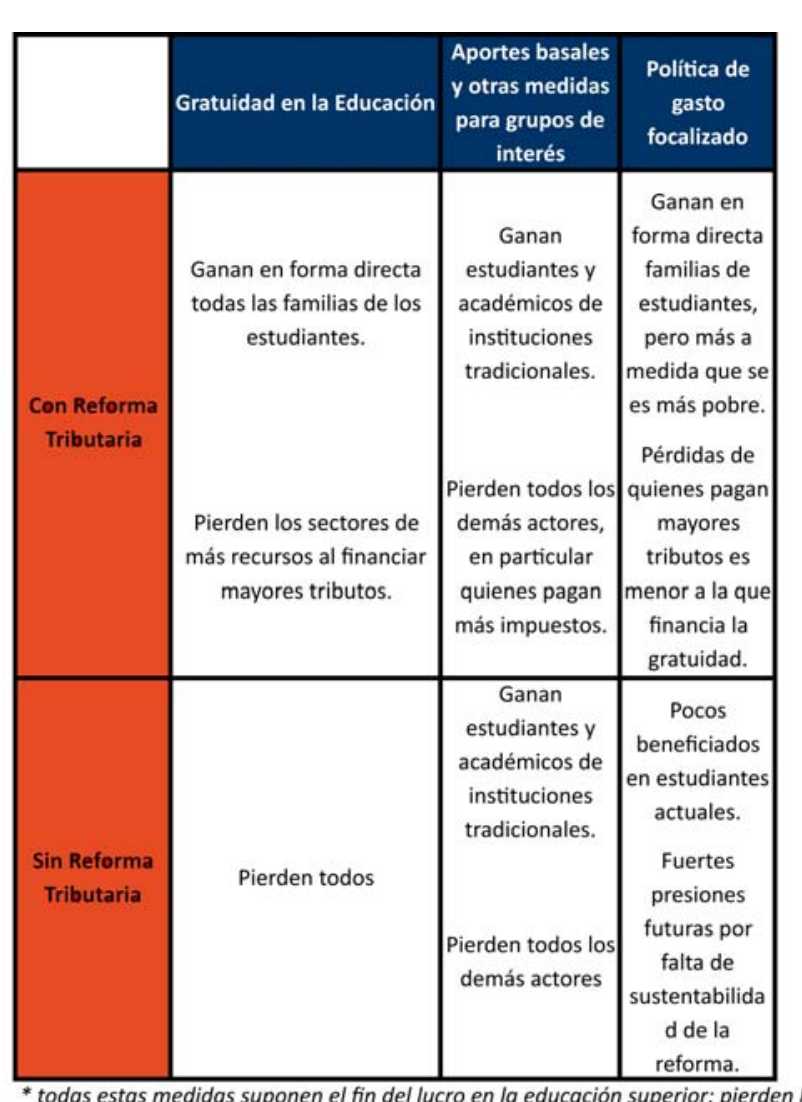


poco sustento, salvo el ser un complemento la competencia en la educación universitaria. En otras palabras: los aportes basales solicitados para las universidades públicas son niños de pecho ante esta petición de perior.

En un contexto de ganadores y perdedores, y considerando además a los que hablan poco y que son los miles de usuarios del sistema, parece correcto aventurar que la única medida de las mencionadas que tiene sustento y coherencia es la que plantean con màs fuerza los estudiantes más radicales: gratuidad de la enseñanz é sustento de largo aliento a esta medda. Sin embargo, y tal como el gobierno da debe ser contrastada con la opción de una educación no discriminatoria que no distinga entre quién la imparte, pero que asegure la calidad y controle que las insttuciones de educación superior no tenga ines de lucro. Suponiendo que es posib evitar el lobby de las universidades estatales y privadas tradicionales, una medid que es también coherente y que apunta corazón del problema es otorgar gratuidad hasta los deciles 405 , financiamiento asegurado y subsidiado a una tasa de 29 sea cual sea la institución de estudio para 5a 7) y controlar que no haya (ucciles a creación de una superintendencia que haga cumplir la ley.

Sin duda esta medida también requier de una reforma tributaria, pues detrás de todo lo propuesto no solo está el gasto de las familias, sino la calidad de la educación superior, y por eso es necesario asegurar que la reforma será permanente o, como lo ha adelante, y con tibieza, la pelota... total ya ca proxi a bierno. Esta medida sempre que las instituciones hagan su pega, tiene como ganadores a todos los chilenos, quienes recibirán una educación de calidad, financiada adecuadamente y con un gasto público focalizado en aquellos que realmente la requieren.

La alternativa que plantean los estudiantes apunta a una educación de calidad, pero como el gasto publico sería mucho mayor, necesariamente se requiere un lú de lo qu lo hace la económica, más focalizado. Las otras apciones de gasto mentarias a las de gratuidad son solo pan para unos pocos privilegiados y hambre todos los demás.

Cualquiera sea la opción tomada el nuevo mapa de la educación superior será definitivamente distinto. Quienes deberian perder son las instituciones que han abusado de la fachada de sociedades inmobiliarias y otras martingalas financieras para licuar sus recursos ante una anodina vigilancia del Ministerio de Educación. Por ello, deberia esperarse que sean ellas las que más se opongan a cualquir medida de cambio profundo al fin del Vucro se otro modo, controlado e y privadas que rinvieten sus excedentes mejorar la calidad de su sus excén denerian ser las grandes beneficiadas.

onen de los estudiantes apunta a que el estándar sea igual como en los alumnos del video clip The Wall de Pink Floyd, mientras que una medida de gasto focalizado y control del lucro apunta a fortalecer instituciones con diferentes andares de enseñanza, y que sean los propios estudiantes quienes opten a cual
El FMI y el gasto social

El siguiente párrafo del reciente Informe de perspectivas económicas para Améric Latina y el Caribe difundido por el Fond Monetario Internacional ha parecido sorErender a algunos:

En los paises con una presión tributan relativamente baja (Chile, Mérico, Perü) es necesario llevar a cabo esfuerzos orienados a movilizar ingresos fiscales pa fraestructura de la región tales como bo niveles aún elevados de desigualdad y las necesidades insatisfechas de una clase media en rápida expansión ".

La parte más anecdótica de la sorpres estaria en que el resumen del informe fue léido por un exministro de Hacienda Chile, país donde cobra vigor la presió por aumentar impuestos. Pero más importante: por lo que revela respecto de decir tácito que etiqueta al FMI como un organismo que preferiría impuestos bajos, asto público bajisimo y Estados pequenos. Aunque no se sostenga explicitamente, se critica que alentar ahora un subida de impuestos seria una suerte de guiño tardío a la justicia distributiva, misma justicia que el FMI habria menoscabado en su historia de recetas de ajus con la misma facilidad torpeza

e podría confundir al pirómano con bombero, los mitos y prejuicios sobre FMI suelen lograr arraigo en dirigentes inspirados en el voluntarismo populista an bien representada en esa frase que mejor ganar elecciones con déficit fise Pe perderlas con superivit.

Pues bien, $y$ en su lugar, antes ir a los

datos: todo lo que está diciendo el FMI hoy es aquello que cautela desde su fundación: que la estabilidad económica y fipueden sostenerse si las politicas sociales no están adecuadamente financiadas. Leease: gastos permanentes que no descansen en ingresos permanentes terminan "impuesto-s de programas públicos $\mathrm{y} / \mathrm{o}$ "mpuesto-inflacion" que pagan -

Y si de examinar mitos y prejuicios se trata, un estudio reciente del propio FMI ofrece datos interesantes.

Primero, el aumento del gasto social se aceleró en los paises con programas de programas. Y más se aceleró en los paises de bajo ingreso que tenían programas con el Fondo. del gasto en educación y atención de la salud en los países de bajo ingreso con programas fue, desde 2000 en adelante, más del doble del promedio de 1985-1999. El mismo estudio llega a conclusiones aún más robustas cuando controla estaentar iveles de in preso y las con edades, los onómicas.

Un conal importantisimo por el cual fluyen los programas que contribuyen 0 en educacion y atencón de la salud es el de los impuestos. Las politicas de sanidad financiera crean asi espacio fiscal para la inversión social. No es cierto, entonces, que la disciplina que imponen las politicas del FMI a
Por otro lado, existen paises que aún sin ener programas de crédito con el FMI, se

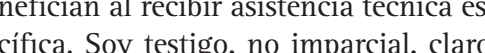
or varios años me ho imparcial, claro. n misiones de asistencia técnica a banon centrales en paises con PIB menor hileno. Puedo dar cuenta y fe de la creacidades de análisis y gestión. aprendizaje para bajar riesgos de pérdta en el manejo de reservas internacionaes en paises donde, como en ningún ot as necesitan líquidas y estables.

Asi pues, sorprenderse de la contribuAsi pus, sopre dalvaguardar la estabilidad no deberia resultar novedoso. ideológica de una determinada recociar gasto permanente.

Los mitos y prejuicios ayudan poco a fortalecimiento del gasto social y

ments Benedict, Sanjeev Gupta y Masahiro Nozaki. What Happens to Social . Washington DC, 20 imf.org/external/pubs/ft/sdn/2011/

Decano: Jorge Rodriguez Grossi. e-mail: jodrigues 7366 economiaynegocios.uahurtado. Producción OE: Comunicar, Escuela de Periodismo UAH. 